\title{
Ten-year experience of an outpatient clinic for CKD-5 patients with multidisciplinary team and educational support
}

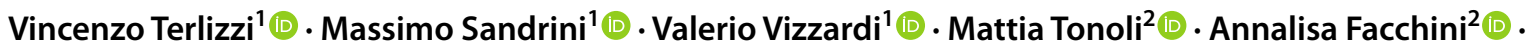 \\ Luigi Manili $^{1}$ (1) $\cdot$ Letizia Zeni $^{1}$ (1) - Giovanni Cancarini ${ }^{1,2}$ (1)
}

Received: 15 January 2021 / Accepted: 7 July 2021 / Published online: 31 July 2021

(c) The Author(s) 2021

\begin{abstract}
Purpose To analyze the results of an outpatient clinic with a multidisciplinary team and educational support for patients with late-stage CKD (lsCKD), to check its possible effect on their outcomes.

Methods Longitudinal cohort study on patients followed up in the MaReA (Malattia Renale Avanzata=CKD5) outpatient clinic at ASST Spedali Civili of Brescia from 2005 to 2015 for at least six months. Trajectory of renal function over time has been evaluated only in those patients with at least four estimations of eGFR before referring to MaReA.

Results Seven hundred and six patients were enrolled, their mean age was $72 \pm 14$ years, 59\% were males. At the end of the study, 147 (21\%) were still on MaReA, 240 (34\%) on dialysis, 92 (13\%) on very low-protein diet (VLPDs), 13 (2\%) on pre-hemodialysis clinic, 23 (3\%) improved renal function, 10 (1\%) transplanted, 62 (9\%) transferred/lost to follow-up, and $119(17 \%)$ died. Optimal dialysis start (defined as start with definitive dialysis access, as an out-patient and without lsCKD complications) occurred in 180/240 (75\%) patients. The results showed a slower eGFR decrease during MaReA follow-up compared to previous renal follow-up: -2.0 vs. $-4.0 \mathrm{~mL} / \mathrm{min} / 1.73 \mathrm{~m}^{2} \mathrm{BSA} /$ year $(p<0.05)$, corresponding to a median delay of 17.7 months in dialysis start in reference to our policy in starting dialysis. The patient cumulative survival was $75 \%$ after 24 months and 25\% after 70. Limitations: (1) lack of a control group, (2) one-center-study, (3) about all patients were Caucasians.
\end{abstract}

Conclusion The follow-up of lsCKD patients on MaReA is associated with an optimal and delayed initiation of dialysis.

Keywords Start of dialysis · Patient survival · GFR trajectory · Delaying dialysis · Optimal start of dialysis · End-stage renal disease

\section{Introduction}

The incidence and prevalence of chronic kidney disease (CKD) are progressively increasing worldwide [1]. In Italy, three studies on the prevalence of CKD show different results: CKD 3-5 stages account for $6 \%$ for patients aged 18-95 years in the GUBBIO Study[2], CKD1-4 12.3\% in

\section{Giovanni Cancarini: Retired.}

Valerio Vizzardi

valerio.vizzardi@asst-spedalicivili.it

1 Operative Unit of Nephrology, ASST Spedali Civili Brescia, Piazzale Spedali Civili, 1, 25123 Brescia, Italy

2 Postgraduate School in Nephrology, University of Brescia, Brescia, Italy people aged over than 40 in the INCIPE Study [3] and 6.3\% in the CARHES Study on 35-79-year-old patients [4].

Although stage 5 represents the most advanced stage of $\mathrm{CKD}$, it is still possible at this stage to reduce the prevalence and severity of end-stage kidney disease-related complications and postpone the need of dialysis [5-7]. Two factors could play impact positively on CKD outcomes: (a) early referral to nephrology care [8-10], (b) outpatient clinic evaluation by a multidisciplinary team, with exposure to educational program and cumulative "dose" of nephrological care. Notably, several works have recently been devoted to these topics [7, 11-15].

The present longitudinal cohort study analyzes a 10-year experience in outpatient clinic dedicated to the End-Stage Kidney Disease ESKD (in Italian: Malattia Renale Avanzata, MaReA) with a multidisciplinary team and educational support. 


\section{Patients and methods}

The MaReA outpatient clinic was born at the Nephrology Operative Unit-ASST Spedali Civili and University of Brescia, in February 2005. Essentially, MaReA includes CKD patients with eGFR $<15 \mathrm{~mL} / \mathrm{min} / 1.73 \mathrm{~m}^{2} \mathrm{BSA}$; however, few patients with several and severe comorbidities have been accepted even with slightly higher values.

The inclusion criteria were: (1) first access to MaReA from 1 February 2005 to 31 August 2015, (2) follow-up at MaReA over a period of time equal or greater than 6 months. For the calculation of changes in trajectory of renal function, a minimum of four estimations on eGFR (by MDRD or CKD-EPI) during the 6 months prior to entry in MaReA were required; this choice was done to ensure more accuracy and reliability in calculating linear regression coefficient. Follow-up ended at the time of last evaluation in MaReA.

MaReA organization is based on a multidisciplinary approach, including different professional healthcare providers as nephrologists, nurses, dieticians, and social workers with the aim to provide patients with a holistic perspective of their chronic condition. The educational support was provided by the nephrologists, at each bimonthly visit, by nurses with 2-4-h meetings and by dieticians for a total of 1.5-2.0-h. At the time of clinical evaluation, patients were screened for any possible lsCKD complications (e.g.: badly controlled blood pressure, nausea, vomiting, hyperkaliemia, fluid overload, metabolic acidosis, malnutrition) and new onset of extra-renal/cardiovascular comorbidities was checked. Changes of pharmacological and dietary therapy, as well as in lifestyle were suggested at the end of clinical evaluation. In case a bimonthly visit was considered insufficient, the subsequent clinical evaluation was scheduled on a tight timeline. Patients were offered the opportunity of an individual meeting with a nurse to receive exhaustive information on principal CKD-related complications, renal replacement therapy strategies and appropriate diet and lifestyle and therefore reinforce and further explain concepts introduced during medical evaluation. From a clinical point of view, attention was focused on self-assessment of hydration status. In addition to medical evaluation and meeting with nurses, patients were referred to a dietitian for a lowprotein and low-salt diet $(0.6-0.8 \mathrm{~g}$ proteins $/ \mathrm{kg} \mathrm{BW}$; and $35 \mathrm{kcal} / \mathrm{kg} /$ day in subjects aged $<60$ years and $30 \mathrm{kcal} / \mathrm{kg} /$ day in those $>60$ years) $[16,17]$ with minimization of potassium and/or phosphate dietary intake and appropriate intake of high biological value proteins from vegetal instead of animal sources.

The diagnostic and therapeutic approach to lsCKD complications has changed and updated consistently to new international/national guidelines procedures on CKD5 published over time (see Appendix 1).
The study was conducted in accordance with the Helsinki Declaration. The data were recorded anonymously and included, clinical information (demography, primary renal disease, type and time of dialysis access, comorbidities, hospitalizations, complications, and outcome) and biochemical parameters: hemoglobin, albumin (Alb), calcium $(\mathrm{Ca})$, phosphate $(\mathrm{P})$, parathyroid hormone $(\mathrm{PTH})$.

The patients were divided into three groups based on the duration of nephrological care: group 1 with less than six visits in MaReA; group 2, from six to ten visits; group 3 more than ten visits. Patients were also classified according to the mode of dialysis start: optimal vs. non-optimal, with 'optimal' meaning start with definitive dialysis access (i.e.: distal or proximal arterio-venous fistula for HD patients and peritoneal catheter for patients starting on peritoneal dialysis), as an out-patient and in the absence of any acute 1sCKD-related complications; non-optimal start was defined as absence of one out of three 'optimal' conditions.

Prior to MaReA follow-up, few patients did not exhibit at least four eGFR estimates (by both MDRD and CKD-EPI formulas). Among those with at least four eGFR estimates before MaReA, the trajectory of renal function (RF) over time was analyzed by means of least squares according to many works recently published [6-9]. The regression line of the pre-MaReA eGFR trajectory has been extrapolated to predict the hypothetical time to start dialysis; the estimate of the delay in starting dialysis was calculated by subtracting this time to the real time when dialysis was started in those patients.

Since the beginning of MaReA practice all clinical and biochemical data were recorded in a FileMaker ${ }^{\circledR}$ file (Apple Inc.; California, USA) and subsequently retrieved in Excel $^{\circledR}$ (Microsoft Office, Microsoft Corporation, Seattle, WA, USA) and eventually analyzed with Statgraphics ${ }^{\circledR}$ (Statpoint Technologies Inc.; Virginia, USA).

Data are reported as mean plus/minus standard deviation or median and interquartile range (IQR), as appropriate. The Chi-square test was used to compare categorical variables, Student's $\mathrm{t}$ test for continuous variables with normal distribution, and Kruskal-Wallis to compare medians. Univariate survival analysis was performed by the Kaplan-Meier method and the curves were compared with the log-rank test. Multivariate survival analysis was performed using the Cox's proportional risk method.

A $p$ value of 0.05 was accepted as statistically significant.

\section{Results}

\section{Population characteristics}

During the period starting from 1 February 2005 to 31 August 2015, 898 patients accessed to MaReA; 706 of them 
(79\%) met inclusion criteria and were enrolled to the study. 414 were males (59\%), with an average age of $72 \pm 14$ years (range: $14-98$ ), BMI $26 \pm 5 \mathrm{~kg} / \mathrm{m}^{2}$ and median follow-up in MaReA 348 days (IQR: 208; 711). Figure 1 shows the flow chart of patient's selection and enrollment. The main characteristics of study population are summarized in Table 1. During the follow-up period, 240 patients started dialysis.

\section{Laboratory tests}

Table 2 summarizes of the laboratory tests performed during the follow-up period. Hemoglobin values $(\mathrm{Hb})$ at the end of the study were statistically lower compared to the beginning $(p<0.05)$. Over time, a statistically significant increase was found in $p(p<0.05)$ and PTH $(p<0.05)$ levels; no significant changes occurred in $\mathrm{Ca}(p=0.88)$ and $\mathrm{Alb}(p=0.74)$.

\section{Outcome and start of dialysis}

At the end of the study, 147 (21\%) patients were still in MaReA follow-up, 240 (34\%) started dialysis, 92 (13\%) were shifted to a very low-protein diet supplemented with

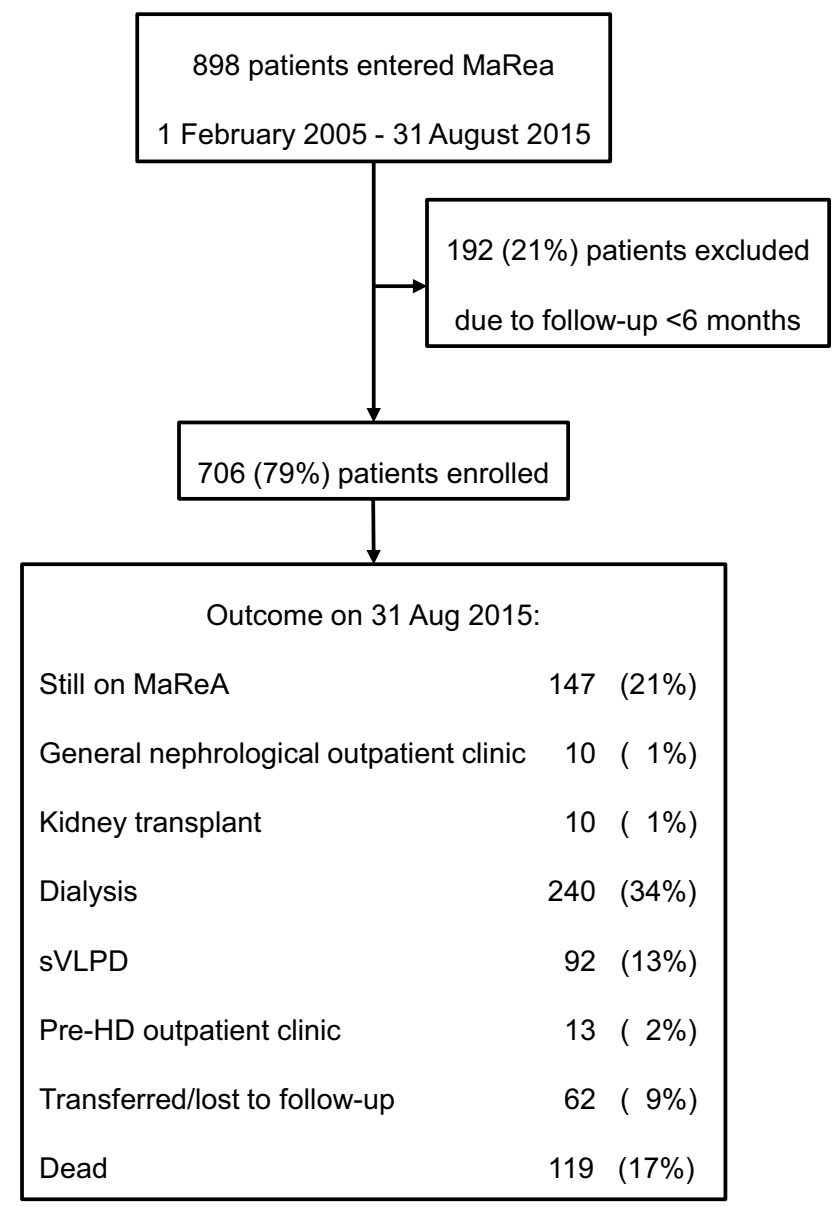

Fig. 1 Flow chart of patient selection and outcome
Table 1 Characteristics of the population studied

\begin{tabular}{ll}
\hline Number of patients & 706 \\
Male gender & $414(59 \%)$ \\
Age (years) & $72 \pm 14$ \\
Ethnicity & \\
Caucasian & $691(98 \%)$ \\
African & $10(1 \%)$ \\
Asian & $5(1 \%)$ \\
Primary renal diseases & \\
Unknown/missing & $288(41 \%)$ \\
Glomerulonephritis & $106(15 \%)$ \\
Diabetic & $101(14 \%)$ \\
Vascular & $98(14 \%)$ \\
Tubular-Interstitial & $50(7 \%)$ \\
ADPKD & $40(6 \%)$ \\
Other & $23(3 \%)$ \\
Comorbidities & \\
Hypertension & $638(90 \%)$ \\
Diabetes mellitus & $282(40 \%)$ \\
Ischemic heart disease & $268(38 \%)$ \\
Cardiac arrhythmia & $258(37 \%)$ \\
Previous diagnosis of malignancy & $228(32 \%)$ \\
Peripheral vasculopathy & $216(31 \%)$ \\
Cerebral vasculopathy & $215(30 \%)$ \\
Urinary tract infection & $179(25 \%)$ \\
Dyslipidemia & $160(23 \%)$ \\
Chronic respiratory disease & $147(21 \%)$ \\
Cirrhosis or chronic liver disease & $101(14 \%)$ \\
\hline &
\end{tabular}

amino acids (VLPDs) 13 (2\%) to pre-hemodialysis clinic (out-patient clinic for patients with already functioning vascular access for hemodialysis, 23 (3\%) to general nephrological outpatient clinic due to partial RF recovery, 10 (1\%) received a kidney transplant, 62 (9\%) were moved to different hospitals / lost to follow-up and 119 (17\%) died. Among patients who started dialysis, $167(70 \%)$ chose hemodialysis and $73(30 \%)$ peritoneal dialysis without statistically significant difference among the three groups of duration of predialysis nephrological care. The main indications for start dialysis were inadequate electrolyte/fluid control and trend toward malnutrition.

The optimal start of dialysis occurred in 180 patients (75\%) without statistically significant difference among the 3 groups of duration of care (Table 3 ).

\section{eGFR change over time}

Progression of renal dysfunction over time has been studied only in those 396 patients (56\%) who had at least four values of eGFR before entering MaReA. The worsening of eGFRCKD-EPI rate was significantly higher before the patients 
entered MaReA than during the follow-up in MaReA: -4.0 $(-7.1 ;-2.2) \mathrm{mL} / \mathrm{min} / 1.73 \mathrm{~m}^{2} \mathrm{BSA} /$ year vs. - 2.0 (- 4.9; - 0.3$) \mathrm{mL} / \mathrm{min} / 1.73 \mathrm{~m}^{2} \mathrm{BSA} /$ year; $(p<0.05)$; similar results were detected for the eGFR by the MDRD equation $(p<0.05)$ (Table 4$)$. The single points of the changes are reported in Fig. 2. The reduction in the rate of worsening of RF can be extrapolated to a median postponement in the start of dialysis of $17.7(1.5 ; 30.3)$ (eGFR by CKD-EPI) months or $16.0(1.6 ; 29.5)$ months (eGFR by MDRD) (Fig. 3).

\section{Hospitalization}

Patients with optimal start of dialysis were hospitalized, during dialysis period, 1.4 times/year vs. 2.1 times/year of patients with non-optimal start $(p<0.001)$; the median days of hospitalization were, 8 (IQR 2-23) per year vs. 20 (IQR 11-57) $(p<0.001)$, respectively. CKD complications occurred more frequently in patients with not-optimal start of dialysis $(p<0.001)$.

No significant differences in the rate of hospitalizations were noticed between the three groups of duration of predialysis nephrological care.

\section{Survival}

Among the 706 patients enrolled in the study, 119 (17\%) died during the follow-up. MaReA patients had 75\% cumulative survival (Kaplan-Meier curve) after 24 months, 50\% after 41 and $25 \%$ after 70 months, respectively.

Patients aged over 75 , had a median survival lower than those younger than 75: 2.82 vs. 4.68 years $(p<0.001)$ at univariate as treated analysis. A significant difference in patient survival was not found neither among the three groups of different duration of nephrological care $(p=0.327)$ nor
Table 2 Laboratory test values during the follow-up

\begin{tabular}{llllll}
\hline & Entry & 6th month & 12th month & EOF & $p$ \\
\hline Hemoglobin (g/dL) & $11.6 \pm 1.4$ & $11.7 \pm 1.5$ & $11.6 \pm 1.3$ & $11.2 \pm 1.4$ & $<0.05$ \\
serum Albumin (g/dL) & $3.8 \pm 0.6$ & $3.9 \pm 0.5$ & $4.0 \pm 0.5$ & $3.8 \pm 0.5$ & NS $(0.74)$ \\
serum Calcium (mg/dL) & $9.1 \pm 0.8$ & $9.2 \pm 0.7$ & $9.2 \pm 0.6$ & $9.1 \pm 0.8$ & NS $(0.88)$ \\
serum Phosphate (mg/dL) & $4.1 \pm 0.9$ & $4.1 \pm 0.8$ & $4.0 \pm 0.8$ & $4.4 \pm 1.1$ & $<0.05$ \\
PTH (pg/mL); & $208(128 ; 336)$ & $219(139 ; 317)$ & $213(134 ; 329)$ & $228(131 ; 394)$ & $<0.05$ \\
\hline
\end{tabular}

Statistical comparison has been done between entry and end of follow-up (EOF): Data reported as $\mathrm{M} \pm \mathrm{SD}$ for Hb, serum Albumin, Calcium and Phosphate, and as median and IQR for PTH

\begin{tabular}{lccllll}
\hline Mode of starting dialysis & Tot & $\%$ & $\begin{array}{l}\text { Group 1 } \\
<6 \\
\text { visits in MaReA }\end{array}$ & $\begin{array}{l}\text { Group 2 } \\
\text { 6-10 visits in } \\
\text { MaReA }\end{array}$ & $\begin{array}{l}\text { Group 3 } \\
>10 \text { visits in } \\
\text { MaReA }\end{array}$ & $p$ \\
\hline (1) with definitive access & 201 & $84 \%$ & $104(82 \%)$ & $55(86 \%)$ & $42(84 \%)$ & 0.83 \\
(2) without complications & 228 & $95 \%$ & $120(95 \%)$ & $62(97 \%)$ & $46(92 \%)$ & 0.49 \\
(3) as outpatient & 203 & $85 \%$ & $103(82 \%)$ & $56(88 \%)$ & $44(88 \%)$ & 0.44 \\
Optimal start $(1+2+3)$ & 180 & $75 \%$ & $91(72 \%)$ & $50(78 \%)$ & $39(78 \%)$ & 0.58 \\
\hline
\end{tabular}

Table 3 "Optimal" dialysis initiation in the 240 patients who started dialysis and comparison of the three groups of patients divided according to the duration of nephrological care given

\begin{tabular}{ccl} 
CKD-EPI & MDRD & $\begin{array}{l}\text { Refer- } \\
\text { ence in } \\
\text { Fig. 1 }\end{array}$ \\
\hline $12.6(10.2 ; 16.0)$ & $14.2(11.4 ; 17.9)$ & A \\
$-4.0(-7.1 ;-2.2)$ & $-4.0(-7.1 ;-2.2)$ & B \\
$6.7(5.3 ; 8.5)$ & $7.7(6.1 ; 9.4)$ & C \\
$17.7(12.3 ; 21.9)$ & $19.5(14.4 ; 24.3)$ & D \\
$-2.0(-4.9 ;-0.3)$ & $-2.2(-4.7 ;-0.3)$ & E \\
$35.4(24.6 ; 43.8)$ & $35.5(26.2 ; 44.2)$ & F \\
$17.7(1.5 ; 30.3)$ & $16.0(1.6 ; 29.5)$ & G \\
\hline
\end{tabular}


Fig. 2 Changes in eGFR with CKD-EPI and MDRD formula before and during MaReA. Seven outliers in each panel have not been shown to increase readability of the figure

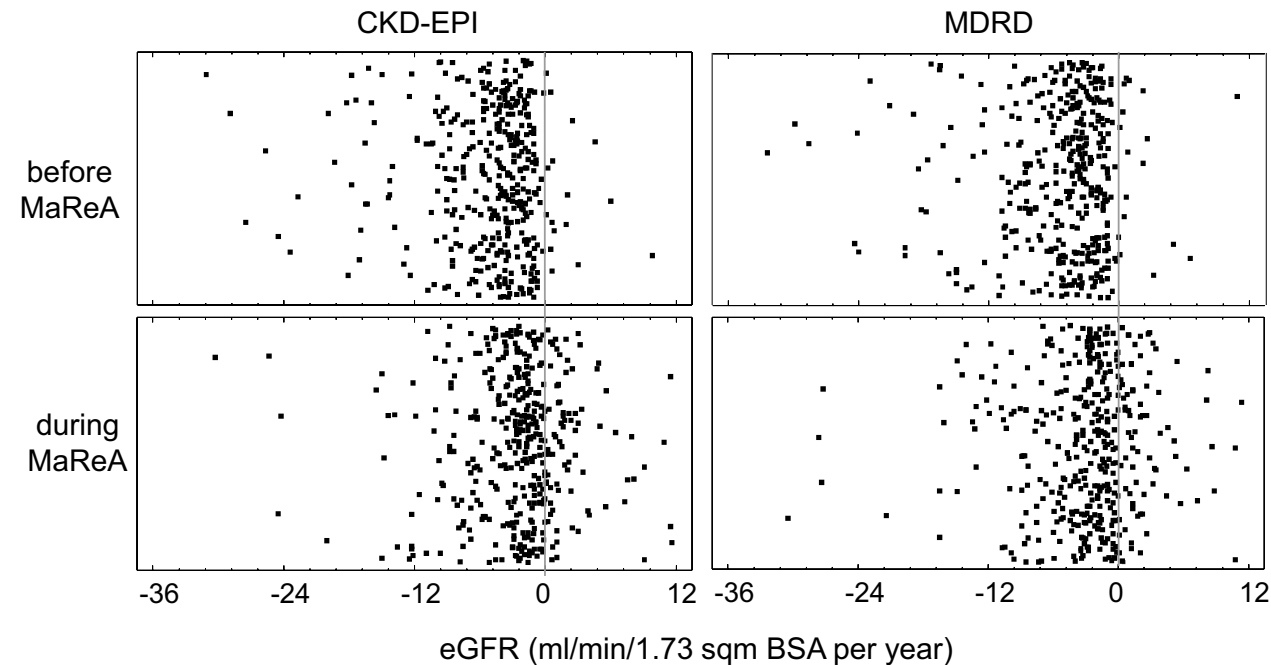

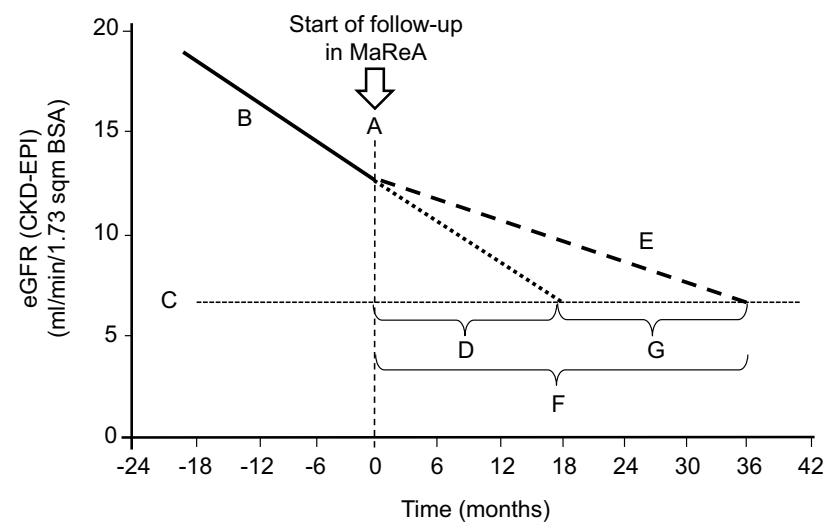

Fig. 3 Median eGFR decrease according to CKD-EPI equation. Continuous line: eGFR decrease in pre-MaReA period; dotted line: expected trajectory of eGFR after starting MaReA, according to the previous decrease rate; dashed line: observed eGFR decrease during MaReA period. See Table 4 for further explanation

between optimal vs. non-optimal start of dialysis comparison $(p=0.380)$.

Cumulative patient survival after starting dialysis was $75 \%$ after 2.9 years and $50 \%$ after 8.5 years.

Cox's analysis showed that the only covariates that significantly affect survival were age at the start of dialysis, diabetes, COPD (Chronic Obstructive Pulmonary Disease) and chronic liver disease (Table 5).

\section{Discussion}

The high prevalence of CKD [1-4], the late referral to nephrologist and the chronic need of dialysis reduce the quality of life of patients and affect negatively healthcare costs.

In this context, nephrologists should make an effort to reduce CKD progression and delay the need of start of
Table 5 Cox analysis for risk of death in dialysis

\begin{tabular}{lllr}
\hline & HR & CI 95\% & \multicolumn{1}{l}{$p$} \\
\hline Age at start of dialysis (years) & 1.099 & $1.066-1.133$ & $<0.001$ \\
Diabetes & 1.816 & $1.127-2.329$ & 0.014 \\
Chronic obstructive pulmonary & 1.691 & $1.019-2.806$ & 0.042 \\
$\quad$ disease & & & \\
Chronic liver disease/cirrhosis & 1.711 & $1.050-2.787$ & 0.031 \\
\hline
\end{tabular}

dialysis. Importantly, one of the mainstays for an accurate and effective management for a chronic condition as CKD is patient educational program. The educational program consists of a multilevel and multidisciplinary approach to provide patient with awareness of his/her disease, related complications, and possible therapeutic options.

The present study reports the results of a 10-year field experience in an outpatient clinic (MaReA) dedicated to CKD5 patients. The studied population was old (72 \pm 14 year) and affected by many co-morbidities (Table 2): almost all patients showed hypertension (90\%), $40 \%$ suffered from diabetes mellitus; $38 \%$ had ischemic heart disease and $32 \%$ had a history of malignancy. The high proportion of patients with unknown etiology of renal disease could depend partly on late referrals and also to our policy of define the etiology of underlined nephropathy only when proved by renal biopsy, sonography imaging, and immunological laboratory test. The high mean age and a median of four comorbidities per patient highlight the frailty of study population.

The laboratory results were satisfactory throughout the follow-up period; hemoglobin was $11.6 \pm 1.4 \mathrm{~g} / \mathrm{dL}$ when patients entered MaReA and showed a statistically significant reduction to $11.2 \pm 1.4 \mathrm{~g} / \mathrm{dL}(p<0.05)$ only at the end of follow-up. However, anemia was barely controlled with $\mathrm{Hb}$ values being over the minimum value recommended by 
KDIGO guidelines [10]. Serum albumin remained stable at3.9 $\mathrm{g} / \mathrm{dL}$ during the follow-up, these data support the efficacy of care in maintaining an adequate nutritional status also in lsCKD [18]. Mineral bone disease control met the recommended targets [19] although a moderate increase in serum phosphate and PTH was observed.

During the follow-up, 240 patients (34\%) started renal replacement treatment; peritoneal dialysis accounted for $30 \%$, the figure is above the average of $26 \%$ of Italian PD Centers in 2014 [20] and the 18\% of our Region Lombardy [21]. These data suggest that that incidence of DP is higher when patients are adequately informed and involved in the choice of dialysis modality [22]. To some extent, time spent in MaReA could have increased knowledge of the disease and helped patients to become more self-confident of home treatment. However, changes in patient self-confidence in home dialysis were not assessed; thus, it remains a mere speculation. The duration of nephrology care did not significantly influence the penetration of peritoneal dialysis in our study, probably because even in patients with a shorter MaReA follow-up, the time was sufficient to provide with adequate information for the choice of dialysis modality.

The optimal start of dialysis is of paramount importance, as demonstrated by its association with a lower mortality rate at 6 months [23]. An optimal start of dialysis occurred in the majority of patients (75\%). In a Canadian series, the corresponding figure was only $40 \%$ of the whole population of 339 patients and mainly initiating with a temporary vascular access [23]. The use of temporary central venous catheters (CVC) is associated with increased inflammatory status and higher mortality [24-26]. CVC were used in $80 \%$ of American patients starting dialysis [27] and in $40 \%$ of incidents dialysis patients in Italy [28]. In our study, a large proportion of patients $(84 \%)$ of patients started hemodialysis with a definitive vascular access. In addition, $85 \%$ of our patients started dialysis as outpatient. The start as out-patient reduces the risks associated with hospitalization and the cost for the National Health Service (NHS). Singhal et al. reported than $60 \%$ of patients with a follow-up of at least 12 months in a pre-dialysis outpatient clinic, started dialysis as out-patients [7]. In 8856 patients from two National French registry, the lack of follow-up with a nephrologist was associated with the start dialysis in emergency [12].

According to the European Renal Best Practice [29], the policy of our Operative Unit of Nephrology is starting dialysis before patients become symptomatic for CKD complications. Obviously, to avoid uremic complications in patients with eGFR between 6 and $9 \mathrm{~mL} / \mathrm{min} / 1.73 \mathrm{~m}^{2} \mathrm{BSA}$, a multilevel and personalized clinical surveillance should be offered. A large number of patients (95\%) started dialysis in the absence of acute uremic complications. An earlier start of dialysis was excluded since median eGFR-CKD-EPI was 6.7 (IQR 5.3; 8.5) $\mathrm{mL} / \mathrm{min} / 1.73 \mathrm{~m}^{2} \mathrm{BSA}$. Although the most appropriate value of eGFR to start dialysis has not been established yet, the Ideal study, the only randomized controlled trial on this topic, did not show differences in mortality between patients with "early-onset" of dialysis $\left(10-15 \mathrm{~mL} / \mathrm{min} / 1.73 \mathrm{~m}^{2} \mathrm{BSA}\right)$ and those ones with "late" start (5-7 mL/min/1.73 $\left.\mathrm{m}^{2} \mathrm{BSA}\right)$ [30].

Many reports suggest that eGFR decrease over time has a linear decline in the majority of CKD5 patients [31] with a worsening rate of $2.2-6.4 \mathrm{~mL} / \mathrm{min} / 1.73 \mathrm{~m}^{2}$ BSA [2, 7-11]. In our study, the worsening rate of eGFR (CKD-EPI) slowed down from $-4.0 \mathrm{~mL} / \mathrm{min} / 1.73 \mathrm{~m}^{2} \mathrm{BSA} /$ year before MaReA to $-2.0 \mathrm{~mL} / \mathrm{min} / 1.73 \mathrm{~m}^{2} \mathrm{BSA} /$ year during MaReA $(p<0.05)$. A reduced worsening rate in eGFR has been reported in patients referred to a multidisciplinary outpatient clinic when compared to patients on "usual care" $(-5.1$ vs $-7.3 \mathrm{~mL} / \mathrm{min} / 1.73 \mathrm{~m}^{2} \mathrm{BSA} /$ year) [33].

This improvement in the trajectory of RF is associated with a delay in the start of dialysis of 17.7 (CKD-EPI) or 16.0 months (MDRD). Postponing dialysis initiation could reduce the number of complications related to dialysis and vascular access, could improve patient quality of life and reduces healthcare costs for NHS. In Italy, the average annual cost for a CKD5 patient in pre-dialysis is about $€$ 5229 [34] much lower than the 26,797 per year on dialysis [35].

Uremic patients are burdened with a high rate of hospitalization. In our series, the median of hospitalization was 1.6 admissions/patient-year equivalent to about 12 days/patientyear, greater than data reported by other centers in Italy [36, 37]. In our series, optimal dialysis start was associated with a $33 \%$ reduction in number of admissions and $60 \%$ of days of hospitalization. The reduction was associated to reduction in hospitalizations due to uremic complications, whereas there was no difference for the other possible causes of admission. These data support the hypothesis that the MaReA clinic could offer good clinical control as suggested by some works supporting that a multidisciplinary approach is the keystone to reduce hospitalizations [33, 38-40].

At the end of the observation, $21 \%$ of patients were still in MaReA while 17\% were died. Median cumulative survival was 40.9 months. The study of Chandna et al' showed a lower median survival (21.2 months vs 40.9 months) in CKD5 patients, but they were older than our patients (77 vs. 72 years)[41].

The cumulative patient survival after starting dialysis was $75 \%$ after 2.9 years and $50 \%$ after 8.5 years; the 2016 ERA-EDTA Registry reports a lower, $45 \%$, 5-year patient survival [42]. This difference could be an effect of the multidisciplinary clinical-educational approach, as suggested by other papers [43-45].

The patient survival in dialysis showed no significant differences between the groups with different duration of care as well as between optimal vs. non-optimal start of dialysis; 
one possible explanation is that the whole population was followed for at least 6 months in MaReA and therefore all of them benefited from a careful management of pre-dialysis complications.

Current literature on conservative, multidisciplinary and educational management of lsCKD is lacking. In the 440 CKD patients reported by Awdishu et al. [11], only 17 were on stage 5 CKD.

Our study has some limitations: the single-center nature, very limited ethnical variability and the absence of a control group. In addition, the hypothetical start time of dialysis is not an actual datum, but an extrapolation based on the changes in eGFR trajectory. On the other hand, some papers support that lower eGFR decrease is strongly associated with the subsequent development of established end points and suggest the possibility of using eGFR decline as a surrogate end point [46-48].

The results of this study suggest that a multidisciplinary team, an educational support and a bimonthly frequency of medical visits could guide patients through the stage 5 CKD safely and is associated with a good nutritional status and an optimal and delayed start of dialysis. Probably, also the earliest stage of renal disease could benefit from multidisciplinary and educational approach, in terms of postponement /avoidance of RRT.

\section{Appendix 1}

Updated Guidelines and Renal Best Practice used as reference for the 1sCKD outpatient clinic. Previous version versions of some guidelines are now not available.

1) Società italiana di nefrologia: Best practice and Procedures.

Websites: https://bestpractice.sinitaly.org/; http:// www.nephromeet.com/web/eventi/NEPHROMEET/ index.cfm; https://documenti.sinitaly.org/linee-guidae-best-practice/; https://documenti.sinitaly.org/malat tia-renale-cronica/; http://www.salute.gov.it/portale/ documentazione/p6_2_2_1.jsp?lingua=italiano\&id= $2244 \&$ id $=2244$

http://www.nephromeet.com/web/lib/Download.cfm?dirdo wnload=E\%3A\%5Cgruppotesi\%5Cdatasite\%5Cnep hromeet \% 5CDocs\%2FDOCSIN\% 5CATT\%5C\&filen ame $=58 \% 5 \mathrm{FLG} \% 5 \mathrm{FMRC} 2012 \% 2 \mathrm{Epdf} \&$ filesavename $=$ LG\%5FMRC2012\%2Epdf\&typeattach=inline

2) Italian ministry of health: Sistema Nazionale della Linee Guida dell'Istituto Superiore di Sanità. Websites: https://www.iss.it/linee-guida1; https://snlg.iss.it/?cat= 59

3) European renal association-European Dialysis Transplantation Association (ERA-EDTA): European renal best practice on CKD. Website: https://www.eraedta.org/en/erbp/guidance/chronic-kidney-disease/posit ion-statements-and-endorsements/

4) Kidney Disease: Improving global outcomes (KDIGO). Website: https://kdigo.org/guidelines/

5) National Kidney Foundation Kidney Disease Outcomes Quality Initiative (NKF-KDOQI). Website: https://www.kidney.org/professionals/guidelines

6) Diagnosis, therapy and care procedures of the ASST Spedali Civili di Brescia. Some of them are common to many hospital wards and some are dedicated only to the Operative Unit of Nephrology. Only for internal use; not available on Internet.

Acknowledgements The authors should thank very much both nurses and dieticians who collaborated to MaReA; they have played an important role in educating and supporting patients.

Author contributions Conceptualization: VT, MS. VV, LM, LZ, GC; methodology: VT, MS, GC; data retrieving: VT, MT, AF, LZ; analysis and investigation: VT. MT, GC; writing-original draft preparation: VT, GC; writing — review and editing: VT, MS, VV, MT, AF, LM, GC; revision and writing the revised version: LZ, GC; supervision: GC.

Funding Open access funding provided by Università degli Studi di Brescia within the CRUI-CARE Agreement.

Availability of data and material Data not available, due to their sensitive nature.

Code availability Data recorded on FileMaker ${ }^{\circledR}$ file (Apple Inc.; California, USA) and retrieved in Excel $^{\circledR}$ (Microsoft Office, Microsoft Corporation, Seattle, WA, USA).

\section{Declarations}

Conflict of interest The authors declare that they have no conflicts of interest.

Research involving human participants This chart review was in accordance with the ethical standards of the institutional and national research committee and with the 1964 Helsinki Declaration and its later amendments or comparable ethical standards.

Consent to participate Before being taken in charge by the outpatient clinic MaReA, all the patients were informed about the modality and goal of this clinic and voluntarily accepted. The data were extracted anonymously by the electronic records. The time period analyzed is 13 years and many patients died or moved elsewhere. For all this reasons, written informed consent is not available.

Open Access This article is licensed under a Creative Commons Attribution 4.0 International License, which permits use, sharing, adaptation, distribution and reproduction in any medium or format, as long as you give appropriate credit to the original author(s) and the source, provide a link to the Creative Commons licence, and indicate if changes were made. The images or other third party material in this article are included in the article's Creative Commons licence, unless indicated otherwise in a credit line to the material. If material is not included in 
the article's Creative Commons licence and your intended use is not permitted by statutory regulation or exceeds the permitted use, you will need to obtain permission directly from the copyright holder. To view a copy of this licence, visit http://creativecommons.org/licenses/by/4.0/.

\section{References}

1. Hill NR, Fatoba ST, Oke JL, Hirst JA, O'Callaghan CA, Lasserson DS, Hobbs FD (2016) Global prevalence of chronic kidney disease-a systematic review and meta-analysis. PLoS ONE 11(7):e0158765. https://doi.org/10.1371/journal.pone.0158765

2. Cirillo M, Laurenzi M, Mancini M, Zanchetti A, Lombardi C, De Santo NG (2006) Low glomerular filtration in the population: prevalence, associated disorders, and awareness. Kidney Int 70(4):800-806. https://doi.org/10.1038/sj.ki.5001641

3. Gambaro G, Yabarek T, Graziani MS, Gemelli A, Abaterusso C, Frigo AC, Marchionna N, Citron L, Bonfante L, Grigoletto F, Tata S, Ferraro PM, Legnaro A, Meneghel G, Conz P, Rizzotti P, D'Angelo A, Lupo A (2010) Prevalence of CKD in northeastern Italy: results of the INCIPE study and comparison with NHANES. Clin J Am Soc Nephrol 5(11):1946-1953. https:// doi.org/10.2215/cjn.02400310

4. Conte G, Pacilio M, Garofalo C, Liberti ME, Provenzano M, Santangelo S (2014) Epidemiology of CKD in Italy and prevention strategies. G Ital Nefrol 31(4):11

5. Devins GM, Mendelssohn DC, Barre PE, Binik YM (2003) Predialysis psychoeducational intervention and coping styles influence time to dialysis in chronic kidney disease. Am J Kidney Dis 42(4):693-703. https://doi.org/10.1053/S0272-6386(03) 00835-7

6. Thilly N, Boini S, Loos-Ayav C, Kessler M, Briancon S, Frimat L (2012) Impact of predialysis therapeutic practices on patient outcomes during the first year of dialysis: the Pharmacoepidemiologic AVENIR study. Med Care 50(1):35-42. https://doi.org/ 10.1097/MLR.0b013e3181d56926

7. Singhal R, Hux JE, Alibhai SM, Oliver MJ (2014) Inadequate predialysis care and mortality after initiation of renal replacement therapy. Kidney Int 86(2):399-406. https://doi.org/10.1038/ ki.2014.16

8. Chan MR, Dall AT, Fletcher KE, Lu N, Trivedi H (2007) Outcomes in patients with chronic kidney disease referred late to nephrologists: a meta-analysis. Am J Med 120(12):1063-1070. https://doi.org/10.1016/j.amjmed.2007.04.024

9. Huisman RM (2004) The deadly risk of late referral. Nephrol Dial Transplant 19(9):2175-2180. https://doi.org/10.1093/ndt/gfh409

10. Drueke TB, Parfrey PS (2012) Summary of the KDIGO guideline on anemia and comment: reading between the (guide)line(s). Kidney Int 82(9):952-960. https://doi.org/10.1038/ki.2012.270

11. Awdishu L, Moore T, Morrison M, Turner C, Trzebinska D (2019) A primer on quality assurance and performance improvement for interprofessional chronic kidney disease care: a path to joint commission certification. Pharmacy (Basel) 7(3):83. https://doi.org/ 10.3390/pharmacy7030083

12. Raffray M, Vigneau C, Couchoud C, Bayat S (2020) Predialysis care trajectories of patients with ESKD starting dialysis in emergency in France. Kidney Int Rep. 6(1):156-167. https://doi.org/ 10.1016/j.ekir.2020.10.026

13. Smart NA, Titus TT (2011) Outcomes of early versus late nephrology referral in chronic kidney disease: a systematic review. Am J Med 124(11):1073-80.e2. https://doi.org/10.1016/j.amjmed.2011. 04.026

14. Shukla AM, Hinkamp C, Segal E, Ozrazgat Baslanti T, Martinez T, Thomas M, Ramamoorthy R, Bozorgmehri S (2019) What do the US advanced kidney disease patients want? Comprehensive pre-ESRD Patient Education (CPE) and choice of dialysis modality. PLoS ONE 14(4):e0215091. https://doi.org/10.1371/journal. pone.0215091

15. Stallings TL, Temel JS, Klaiman TA, Paasche-Orlow MK, Alegria M, O'Hare A, O'Connor N, Dember LM, Halpern SD, Eneanya ND (2021) Integrating conservative kidney management options and advance care planning education (COPE) into routine CKD care: a protocol for a pilot randomised controlled trial. BMJ Open 11(2):e042620. https://doi.org/10.1136/bmjopen-2020-042620

16. Cupisti A, Brunori G, Di Iorio R, D'Alessandro C, Pasticci F, Cosola $\mathrm{C}$ et al (2018) Nutritional treatment of advanced CKD: twenty consensus statements. J Nephrol 31(4):457-473. https:// doi.org/10.1007/s40620-018-0497-z

17. Bellizzi V, Cupisti A, Locatelli F, Bolasco PG, Brunori G, Cancarini $\mathrm{G}$ et al (2016) Low-protein diets for chronic kidney disease patients: the Italian experience. BMC Nephrol 17:77. https://doi. org/10.1186/s12882-016-0280-0

18. Ikizler TA (2007) Protein and energy intake in advanced chronic kidney disease: how much is too much? Semin Dial 20(1):5-11. https://doi.org/10.1111/j.1525-139X.2007.00231.X

19. Ketteler MBG, Evenepoel $P$ et al (2017) Executive summary of the 2017 KDIGO Chronic Kidney Disease-Mineral and Bone Disorder (CKD-MBD) Guideline Update: what's changed and why it matters. Kidney Int 92(1):26-36. https://doi.org/10.1016/j.kint. 2017.04.006 (Kidney international 92 (6):1558. doi:10.1016/j. kint.2017.10.001)

20. Marinangeli G, Neri L, Viglino G, Rocca AR, Laudon A, Ragusa A, Cabiddu G (2018) PD in Italy: the 5th GSDP-SIN Census 2014. G Ital Nefrol 35(5):22-41

21. Società Italiana di Nefrologia. Registro Dialisi e Trapianto Regione Lombardia. https://ridt.sinitaly.org/2017/03/18/2015-2/

22. Devoe DJ, Wong B, James MT, Ravani P, Oliver MJ, Barnieh L, Roberts DJ, Pauly R, Manns BJ, Kappel J, Quinn RR (2016) Patient education and peritoneal dialysis modality selection: a systematic review and meta-analysis. Am J Kidney Dis 68(3):422433. https://doi.org/10.1053/j.ajkd.2016.02.053

23. Mendelssohn DC, Curtis B, Yeates K, Langlois S, MacRae JM, Semeniuk LM, Camacho F, McFarlane P (2011) Suboptimal initiation of dialysis with and without early referral to a nephrologist. Nephrol Dial Transplant 26(9):2959-2965. https://doi.org/ 10.1093/ndt/gfq843

24. Banerjee T, Kim SJ, Astor B, Shafi T, Coresh J, Powe NR (2014) Vascular access type, inflammatory markers, and mortality in incident hemodialysis patients: the Choices for Healthy Outcomes in Caring for End-Stage Renal Disease (CHOICE) Study. Am J Kidney Dis 64(6):954-961. https://doi.org/10.1053/j.ajkd.2014. 07.010

25. Ozeki T, Shimizu H, Fujita Y, Inaguma D, Maruyama S, Ohyama Y, Minatoguchi S, Murai Y, Terashita M, Tagaya T (2017) The type of vascular access and the incidence of mortality in Japanese dialysis patients. Intern Med (Tokyo, Japan) 56(5):481-485. https://doi.org/10.2169/internalmedicine.56.7563

26. Soleymanian T, Sheikh V, Tareh F, Argani H, Ossareh S (2017) Hemodialysis vascular access and clinical outcomes: an observational multicenter study. J Vasc Access 18(1):35-42. https://doi. org/10.5301/jva.5000610

27. Collins AJ, Foley RN, Chavers B, Gilbertson D, Herzog C, Johansen K et al (2012) 'United States Renal Data System 2011 Annual Data Report: Atlas of chronic kidney disease \& end-stage renal disease in the United States. Am J Kidney Dis 59(1 Suppl 1):A7, e1-420. https://doi.org/10.1053/j.ajkd.2011.11.015

28. Ethier J, Mendelssohn DC, Elder SJ, Hasegawa T, Akizawa T, Akiba T, Canaud BJ, Pisoni RL (2008) Vascular access use and outcomes: an international perspective from the Dialysis 
Outcomes and Practice Patterns Study. Nephrol Dial Transplant 23(10):3219-3226. https://doi.org/10.1093/ndt/gfn261

29. Tattersall J, Dekker F, Heimburger O, Jager KJ, Lameire N, Lindley E, Van Biesen W, Vanholder R, Zoccali C (2011) When to start dialysis: updated guidance following publication of the Initiating Dialysis Early and Late (IDEAL) study. Nephrol Dial Transplant 26(7):2082-2086. https://doi.org/10.1093/ndt/gfr168

30. Cooper BA, Branley P, Bulfone L, Collins JF, Craig JC, Fraenkel MB, Harris A, Johnson DW, Kesselhut J, Li JJ, Luxton G, Pilmore A, Tiller DJ, Harris DC, Pollock CA (2010) A randomized, controlled trial of early versus late initiation of dialysis. N Engl J Med 363(7):609-619. https://doi.org/10.1056/NEJMoa1000552

31. Boucquemont J, Loubere L, Metzger M, Combe C, Stengel B, Leffondre K (2017) Identifying subgroups of renal function trajectories. Nephrol Dial Transplant 32(suppl_2):ii185-ii193. https:// doi.org/10.1093/ndt/gfw380

32. O'Hare AM, Bertenthal D, Walter LC, Garg AX, Covinsky K, Kaufman JS, Rodriguez RA, Allon M (2007) When to refer patients with chronic kidney disease for vascular access surgery: should age be a consideration? Kidney Int 71(6):555-561. https:// doi.org/10.1038/sj.ki.5002078

33. Chen YR, Yang Y, Wang SC, Chiu PF, Chou WY, Lin CY, Chang JM, Chen TW, Ferng SH, Lin CL (2013) Effectiveness of multidisciplinary care for chronic kidney disease in Taiwan: a 3-year prospective cohort study. Nephrol Dial Transplant 28(3):671-682. https://doi.org/10.1093/ndt/gfs469

34. Turchetti G, Bellelli S, Amato M, Bianchi S, Conti P, Cupisti A, Panichi V, Rosati A, Pizzarelli F (2017) The social cost of chronic kidney disease in Italy. Eur J Health Econ 18(7):847-858. https:// doi.org/10.1007/s10198-016-0830-1

35. Piccoli GB, Ferraresi M, Caputo F, Quarello F, Vigano MR, Mascia F, Gesualdo L (2012) Home hemodialysis and peritoneal dialysis compared. G Ital Nefrol 29(2):148-159

36. Brunori G, Camerini C, Cancarini G, Manili L, Sandrini S, Movilli E, Galvani G, Maiorca R (1992) Hospitalization: CAPD versus hemodialysis and transplant. Adv Perit Dial 8:71-74

37. Di Napoli A, Pezzotti P, Di Lallo D, Tancioni V, Papini P, Guasticchi G (2005) Determinants of hospitalization in a cohort of chronic dialysis patients in central Italy. J Nephrol 18(1):21-29

38. Yu YJ, Wu IW, Huang CY, Hsu KH, Lee CC, Sun CY, Hsu HJ, Wu MS (2014) Multidisciplinary predialysis education reduced the inpatient and total medical costs of the first 6 months of dialysis in incident hemodialysis patients. PLoS ONE 9(11):e112820. https://doi.org/10.1371/journal.pone.0112820

39. Chen YR, Yang Y, Wang SC, Chou WY, Chiu PF, Lin CY, Tsai WC, Chang JM, Chen TW, Ferng SH, Lin CL (2014) Multidisciplinary care improves clinical outcome and reduces medical costs for pre-end-stage renal disease in Taiwan. Nephrology (Carlton) 19(11):699-707. https://doi.org/10.1111/nep.12316

40. Cho EJ, Park HC, Yoon HB, Ju KD, Kim H, Oh YK, Yang J, Hwang YH, Ahn C, Oh KH (2012) Effect of multidisciplinary predialysis education in advanced chronic kidney disease: propensity score matched cohort analysis. Nephrology (Carlton) 17(5):472479. https://doi.org/10.1111/j.1440-1797.2012.01598.x

41. Chandna SM, Da Silva-Gane M, Marshall C, Warwicker P, Greenwood RN, Farrington K (2011) Survival of elderly patients with stage 5 CKD: comparison of conservative management and renal replacement therapy. Nephrol Dial Transplant 26(5):1608-1614. https://doi.org/10.1093/ndt/gfq630

42. van de Luijtgaarden MW, Jager KJ, Segelmark M, Pascual J, Collart F, Hemke AC, Remon C, Metcalfe W, Miguel A, Kramar R, Aasarod K, Abu Hanna A, Krediet RT, Schon S, Ravani P, Caskey FJ, Couchoud C, Palsson R, Wanner C, Finne P, Noordzij M (2016) Trends in dialysis modality choice and related patient survival in the ERA-EDTA Registry over a 20 -year period. Nephrol Dial Transplant 31(1):120-128. https://doi.org/10.1093/ndt/ gfv295

43. Yeoh HH, Tiquia HS, Abcar AC, Rasgon SA, Idroos ML, Daneshvari SF (2003) Impact of predialysis care on clinical outcomes. Hemodial Int 7(4):338-341. https://doi.org/10.1046/j.1492-7535. 2003.00059.x

44. Goldstein M, Yassa T, Dacouris N, McFarlane P (2004) Multidisciplinary predialysis care and morbidity and mortality of patients on dialysis. Am J Kidney Dis 44(4):706-714

45. Curtis BM, Ravani P, Malberti F, Kennett F, Taylor PA, Djurdjev O, Levin A (2005) The short- and long-term impact of multidisciplinary clinics in addition to standard nephrology care on patient outcomes. Nephrol Dial Transplant 20(1):147-154. https:// doi.org/10.1093/ndt/gfh585

46. Coresh J, Turin TC, Matsushita K, Sang Y, Ballew SH, Appel LJ, Arima H, Chadban SJ, Cirillo M, Djurdjev O, Green JA, Heine GH, Inker LA, Irie F, Ishani A, Ix JH, Kovesdy CP, Marks A, Ohkubo T, Shalev V, Shankar A, Wen CP, de Jong PE, Iseki K, Stengel B, Gansevoort RT, Levey AS (2014) Decline in estimated glomerular filtration rate and subsequent risk of end-stage renal disease and mortality. JAMA 311(24):2518-2531. https://doi.org/ 10.1001/jama.2014.6634

47. Inker LA, Lambers Heerspink HJ, Mondal H, Schmid CH, Tighiouart H, Noubary F, Coresh J, Greene T, Levey AS (2014) GFR decline as an alternative end point to kidney failure in clinical trials: a meta-analysis of treatment effects from 37 randomized trials. Am J Kidney Dis 64(6):848-859. https://doi.org/10.1053/j. ajkd.2014.08.017

48. Lambers Heerspink HJ, Tighiouart H, Sang Y, Ballew S, Mondal H, Matsushita K, Coresh J, Levey AS, Inker LA (2014) GFR decline and subsequent risk of established kidney outcomes: a meta-analysis of 37 randomized controlled trials. Am J Kidney Dis 64(6):860-866. https://doi.org/10.1053/j.ajkd.2014.08.018

Publisher's Note Springer Nature remains neutral with regard to jurisdictional claims in published maps and institutional affiliations. 